\title{
DAÑO OXIDATIVO EN LA MICROALGA Pseudokirchneriella subcapitata EXPUESTA A AGUAS RECEPTORAS DE UN EFLUENTE MINERO EN DEL RÍO BLANCO (V REGIÓN, CHILE)
}

\author{
Fernanda Aránguiz y Hernán Gaete* \\ Departamento de Biología y Ciencias Ambientales, Facultad de Ciencias, Universidad de Valparaíso, Av. Gran Bretaña 1111, \\ Valparaíso, Chile \\ María Eliana Hidalgo y Gabriela Lobos \\ Departamento de Química y Bioquímica, Facultad de Ciencias, Universidad de Valparaíso, Av. Gran Bretaña 1111, Valparaíso, Chile
}

Recebido em 5/3/09; aceito em 19/5/09; publicado na web em 20/10/09

\begin{abstract}
OXIDATIVE DEMAGE IN THE MICROALGAE Pseudokirchneriella subcapitata EXPOSED TO RECEIVING WATERS OF A MINING EFFLUENT IN THE RIO BLANCO (V REGION, CHILE). In this investigation antioxidant response and toxicity of metals in receiving water effluent miner in the Blanco river in Pseudokirchneriella subcapitata was assessed. The catalase activity, lipid damage through Tbars, the growth rate of was determined. The result showed an inhibition of the growth rate of $P$. subcapitata which correlated with increased catalase activity and the lipid liperoxidation. These responses were correlated with the concentrations of copper and iron.
\end{abstract}

Keywords: copper; oxidative stress; antioxidants Pseudokirchneriella subcapitata.

\section{INTRODUCCIÓN}

El oxígeno es esencial para el metabolismo de los organismos aerobios, sin embargo, su participación en el metabolismo celular resulta en la producción de las especies reactivas de oxigeno, como el anión radical superóxido, radical hidróxilo, el peróxido de hidrógeno y el oxígeno singulete. Varios agentes como los metales, luz ultravioleta, temperaturas extremas y otros contaminantes están asociados con la sobreproducción de especies tóxicas de oxígeno y daño celular en los productores primarios. ${ }^{1,2}$

Durante el metabolismo celular, una pequeña proporción (2-3\%) de las especies reactivas de oxígeno puede escapar del rol protector de los mecanismos antioxidantes, causando daño oxidativo a los componentes celulares. El desequilibrio entre la producción y la neutralización de las especies reactivas de oxígeno por los mecanismos antioxidantes se llama estrés oxidativo. Estas formas tóxicas del oxígeno pueden reaccionar con los ácidos nucleicos, proteínas, lípidos, pigmentos y otras biomoléculas, causando su degradación. ${ }^{1,3}$

Un efecto dañino de las especias reactivas de oxigeno es la peroxidación lipídica de la membrana, la cual es detectada y cuantificada midiendo el malondialdehído (MDA) y otros productos de la lipoperoxidación, los que forman complejos coloreados al reaccionar con el ácido tiobarbitúrico. La lipoperoxidación está relacionada con el aumento de la permeabilidad de iones, uniones entre lípidos y polipéptidos y la inactivación de proteínas y enzimas de la membrana. ${ }^{1}$

Los organismos aerobios poseen mecanismos de defensa antioxidante dedicados a prevenir el daño celular producido por las especies reactivas de oxígeno, ${ }^{3,4}$ entre los que figuran una variedad de sistemas de defensa antioxidante tanto enzimático como no enzimático, que se coordinan cooperativamente y protegen al organismo de los riesgos que conllevan el estrés oxidativo. Entre ellos destacan las actividades enzimáticas superóxido dismutasa (SOD), catalasa (CAT), glutatión peroxidasa (GPX), así como el glutatión (GSH), además del ácido ascórbico (vitamina C), alfa-tocoferol (vitamina E), betacaroteno, vitamina A, flavonoides y polifenoles. ${ }^{3-5}$

Los organismos vivos tienen la habilidad de sintetizar y controlar sistemas enzimáticos específicos utilizados para reparar y remover el daño a proteínas, lípidos y ADN. Además, debido a que los niveles de

*e-mail: hernan.gaete@uv.cl estrés oxidativo pueden variar con el tiempo, los organismos pueden adaptarse a dichas variaciones estresantes induciendo la síntesis adicional de enzimas antioxidantes para regular el daño oxidativo. ${ }^{3}$

El cobre es un micronutriente esencial para el crecimiento de los organismos vivos, pero es requerido solo en cantidades traza, ya que a altas concentraciones es toxico para las células al alterar las funciones de las proteínas y consecuentemente la actividad enzimática. ${ }^{6,7}$ El cobre se encuentra normalmente como complejos en las proteínas de las células y si se encuentra como ion libre puede generar estrés oxidativo y daños serios en macromoléculas. ${ }^{7}$

La actividad de enzimas antioxidantes como la catalasa (CAT) son útiles biomarcadores para evaluar la presencia de estrés oxidativo en plantas inducido por metales, pesticidas y otros contaminantes. ${ }^{6,8}$

Existe evidencia que el cobre induce la producción de especies reactivas de oxigeno (ERO) en plantas, que como respuesta, pueden accionar sus sistemas de defensa celular activando las actividades enzimáticas antioxidantes. ${ }^{6}$

En los ecosistemas acuáticos los organismos que pueden ser afectados por agentes químicos potencialmente tóxicos son los productores primarios, los cuales son claves en su estructura y funcionamiento,,${ }^{4,9}$ por lo que cualquier efecto negativo sobre ellos afectará los niveles tróficos superiores. En la actividad minera se liberan metales los cuales pueden alcanzar las aguas superficiales pudiendo provocar efectos tóxicos en los productores primarios a través de la generación de especies reactivas de oxígeno.

La microalga de agua dulce Pseudokirchneriella subcapitata se encuentra entre las más utilizadas en pruebas de toxicidad, ${ }^{10}$ lo que facilita la evaluación de la relación entre defensas antioxidantes y respuestas de toxicidad, que pueden ayudar a entender el papel fisiológico de estos sistemas en especies relacionadas. El objetivo de esta investigación fue evaluar la respuesta antioxidante a metales y la toxicidad de aguas superficiales receptoras de un efluente minero en el río Blanco sobre la microalga Pseudokirchneriella subcapitata.

\section{PARTE EXPERIMENTAL}

\section{Muestreo}

Las muestras de agua fueron tomadas en recipientes plásticos en 4 puntos de muestreo en el río Blanco en función de la descarga del 
efluente de la industria minera: primero en el efluente de la industria de molibdeno, segundo antes de la descarga del efluente de la industria de molibdeno denominado preimpacto; tercero en la zona de descarga del efluente denominado impacto y cuarto aguas debajo de la descarga del efluente de la industria denominado postimpacto. Los punto de muestreo está a una altitud aproximada de $1600 \mathrm{~m}$ sobre el nivel del mar. Estos muestreos se realizaron en septiembre y diciembre de 2006 y en abril de 2007, de acuerdo a la norma NCh411/6.Of98, Calidad del agua-Muestreo (Figura 1). ${ }^{11}$ Las muestras fueron transportadas refrigeradas $\left(4^{\circ} \mathrm{C}\right)$ a la Universidad de Valparaíso y procesadas antes de $24 \mathrm{~h}$ de colectadas. En diciembre no hay datos en la estación de impacto ya que no se pudo tener acceso a este punto de muestreo, debido al aumento del caudal del río Blanco.

La determinación de $\mathrm{pH}$, conductividad, temperatura y sólidos disueltos totales (SDT) se realizó in situ con un equipo multiparámetro Hanna HI 98130, y la determinación de las variables oxígeno disuelto (OD) y porcentaje de saturación de oxígeno se realizó con un equipo Labcor Consort C534.

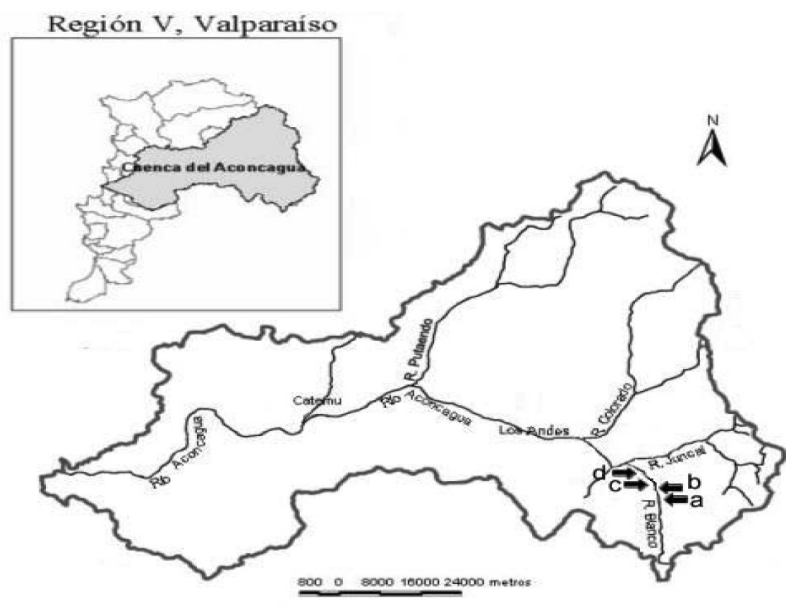

Figura 1. Localización de los puntos de muestreo en la zona de estudio (río Blanco). Estación de preimpacto (a), efluente (b), impacto (c) y postimpacto $(d)$

\section{Análisis químico}

Se determinaron las concentraciones totales y disueltas de cobre, hierro, zinc, y molibdeno (previa digestión ácida-oxidante) mediante espectroscopia de emisión atómica con plasma inductivamente acoplado (ICP-OES) y As mediante HG-ICP-OES.

\section{Bioensayos de inhibición de la tasa de crecimiento en microalgas}

Como organismo de prueba, se utilizó la microalga unicelular de agua dulce Pseudokirchrneriella subcapitata, perteneciente al orden Chlorococcales clase Chlorophyceae, división Chlorophyta. La cepa fue adquirida en el Laboratorio de Ficología de la Universidad de Concepción. Los bioensayos fueron realizados de acuerdo con el procedimiento a la norma NCh2709/Of2002. ${ }^{12}$

Previo a cada bioensayo se prepararon las soluciones de nutrientes compuestas por Fe-EDTA, micronutrientes: $\mathrm{B}, \mathrm{Mn}$, Zn, Co, Mo, y macronutrientes: N, P, Mg, Ca, S, K, Na. Luego, en matraces Erlenmeyer, se inocularon las muestras de agua de río con un mismo volumen de Pseudokirchneriella subcapitata de un medio de cultivo que se encontraba en fase exponencial de crecimiento y fueron enriquecidas con una misma concentración de nutrientes para evitar falsos negativos debido a la deficiencia de nutrientes. Adicionalmente una solución control preparada con agua destilada, reemplazando el agua de río, fue enriquecida con los mismos nutrientes. La concentración celular inicial fue de 100.000 células $/ \mathrm{mL}$. Cada una de las muestras y control tuvieron cuatro réplicas. Los tratamientos resultantes con volumen de $50 \mathrm{~mL}$ se mantuvieron bajo luz blanca fría continua con una intensidad lumínica de $90 \mu \mathrm{mol} \mathrm{m} \mathrm{m}^{-2} \mathrm{~s}^{-1} \pm 10 \mu \mathrm{mol} \mathrm{m} \mathrm{m}^{-2} \mathrm{~s}^{-1}$, a una temperatura de $23 \pm 2{ }^{\circ} \mathrm{C}$ y con agitación manual dos veces al día.

La densidad celular (N) se determinó cada 24 h por conteo directo en microscopio utilizando cámara de Neubauer de línea brillante durante 96 h y se determinó la tasa de crecimiento k en número de divisiones celulares por día (divisiones/día) a partir de $k=3,322 \frac{\log N_{n}-\log N_{0}}{t_{n}}$, donde $N_{n}$ es la densidad celular al final del bioensayo; $N_{o}$ es la densidad celular inicial nominal y $t_{n}$ es el tiempo transcurrido entre el inicio y final del bioensayo (en días). También se determinó el porcentaje de inhibición de la tasa de crecimiento $\left(\mathrm{I}_{\mathrm{k}}\right)$ como $I_{k}=\frac{k_{c}-k_{i}}{k_{c}} \times 100$; en donde $k_{c}$ es la tasa de crecimiento para la concentración $k$; y $k_{i}$ corresponde a la tasa de crecimiento promedio para el control. ${ }^{12}$ La correlación entre variables se determinó por análisis de Pearson y la significancia de la diferencia entre medias se realizó mediante la prueba T de Student. Para ello se utilizó el programa Systat.

\section{Evaluación de la respuesta antioxidante en Pseudokirchneriella subcapitata}

Para evaluar la respuesta antioxidante de la microalga se prepararon cultivos de $300 \mathrm{~mL}$ en matraces con muestras de agua de río de las estaciones mencionadas anteriormente, además se preparó un control de laboratorio reemplazando el agua de río con agua destilada. Cada uno de los cultivos (muestras de agua y control de laboratorio) fueron enriquecidos con una misma concentración de nutrientes y preparados en triplicado. Los cultivos se mantuvieron por 13-15 días. ${ }^{4}$

A los 15 días se determinó la densidad celular en los cultivos y fueron centrifugados a $4000 \mathrm{rpm}$, se obtuvo el concentrado de células y se congeló con nitrógeno líquido, se molió en un mortero y se extrajo con $2 \mathrm{~mL}$ de buffer fosfato de sodio $50 \mathrm{mM}(\mathrm{pH} 7,0),{ }^{7,13}$ los aproximadamente $3 \mathrm{~mL}$ obtenidos son separados en dos partes, la primera de $1 \mathrm{~mL}$ para la determinación de productos reactivos al ácido tiobarbitúrico y la segunda, de $2 \mathrm{~mL}$ para la determinación de la actividad enzimática de la catalasa.

\section{Determinación de productos reactivos al ácido tiobarbitúrico (TBARS)}

Los productos de la lipoperoxidación reaccionan con el ácido tiobarbitúrico generando compuestos coloreados que absorben en el espectro visible $(535 \mathrm{~nm}) .^{14,15}$

Luego de congelar, moler y extraer con buffer fosfato de sodio, se separaron las proteínas de $1 \mathrm{~mL}$ de muestra por precipitación con $1 \mathrm{~mL}$ de ácido tricloroacético $(30 \%$ p/v), se centrifugó y $1,5 \mathrm{~mL}$ de sobrenadante se hizo reaccionar con $1 \mathrm{~mL}$ de ácido tiobarbitúrico $(0,67 \% \mathrm{p} / \mathrm{v})$ calentando en baño maría hirviente por $20 \mathrm{~min}$ y una vez frío, a partir del espectro de absorción entre 450 y $600 \mathrm{~nm}$, se determinó el pico a $535 \mathrm{~nm}$ en un espectrofotómetro Cecil 2041. Los resultados se expresan en nanomoles de MDA/ $10^{6}$ células desde una curva de calibración con MDA puro. ${ }^{1,45,13}$

\section{Determinación de la actividad enzimática de la catalasa}

La actividad de la catalasa se determinó en base a la cinética de 
degradación del peróxido de hidrógeno $\left(\mathrm{H}_{2} \mathrm{O}_{2}\right)$, que es acelerada en presencia de la enzima, según la siguiente reacción:

$$
2 \mathrm{H}_{2} \mathrm{O}_{2} \stackrel{\text { CAT }}{\longrightarrow} 2 \mathrm{H}_{2} \mathrm{O}+\mathrm{O}_{2}
$$

Luego de congelar, moler y extraer con buffer fosfato de sodio se centrifugó $2 \mathrm{~mL}$ de muestra y se obtuvo el sobrenadante. En un espectrofotómetro Cecil 2041 se siguió la cinética de degradación de peróxido de hidrógeno 0,3 M midiendo la absorbancia a $240 \mathrm{~nm}$ durante 1 minuto..$^{5,75-17}$ Los resultados se expresan en $\mathrm{U} / 10^{6}$ células. $^{4}$

\section{RESULTADOS Y DISCUSIÓN}

En la Tabla 1, se puede observar que en septiembre y abril el menor $\mathrm{pH}$ se determinó en el efluente de la Planta de Molibdeno ubicada en el sector de estudio, situándose en el rango permitido por la normativa para descargas de residuos líquidos a cuerpos de agua fluviales. ${ }^{18}$ En diciembre la estación con el menor $\mathrm{pH}$ fue la de preimpacto. El $\mathrm{pH}$ fue levemente alcalino en todas las estaciones durante todos los períodos de estudio cumpliendo con la norma para riego. ${ }^{19}$ Estos niveles son similares a los medidos en la zona de estudio por Gaete et al.. ${ }^{20}$

Respecto a los sólidos disueltos totales, temperatura y conductividad los mayores niveles se determinaron en el efluente de la planta de molibdeno (Tabla 1), durante todos los periodos de estudio, afectando sus aguas receptoras. Los niveles de conductividad determinados en la estación de impacto en septiembre corresponden a aguas que puede tener efectos adversos en muchos cultivos y necesita de métodos de manejo cuidadosos. ${ }^{19}$ Estos niveles de conductividad son similares a los determinados por Gaete et al. ${ }^{20}$

Los niveles de sólidos disueltos totales no superan el máximo establecido para aguas destinadas a riego, excepto la estación de impacto en septiembre que corresponde a aguas que pueden tener efectos perjudiciales en cultivos sensibles. ${ }^{19}$

En septiembre y abril la mas alta concentración de oxígeno disuelto se determinó en el efluente, pero en las estaciones de impacto y postimpacto su concentración vuelve a ser similar a la estación de preimpacto. En diciembre la baja concentración de oxígeno disuelto en el efluente parece no influir en la estaciones ubicadas aguas abajo, comparándola con la estación de preimpacto. Las altas concentraciones de oxígeno disuelto en diciembre se pueden explicar por aumento de la turbulencia de las aguas, debido al deshielo de la nieve en la parte alta de la cuenca.

En septiembre la mayor concentración de cobre total se determinó en la estación de impacto, superando el máximo permitido por la normativa, ${ }^{19}$ sin embargo, de la fracción total del metal, sólo el $11 \%$ corresponde a la cobre disuelto, fracción que se considera realmente biodisponible y por lo tanto con actividad tóxica. Esta estación se encuentra aguas abajo de la descarga del efluente minero de la planta de molibdeno, debido a que la concentración de esta forma del metal fue menor en el efluente, podría existir otra fuente del metal. Algo similar ocurrió en diciembre, la menor concentración de cobre total se determinó en el efluente de la planta de molibdeno, y más altas concentraciones totales del metal se determinaron en las estaciones de preimpacto y postimpacto superando también la normativa, ${ }^{19} \mathrm{y}$ donde más del $55 \%$ corresponde a cobre disuelto. En abril la mayor concentración de cobre total se determinó en el efluente, provocando un aumento de la concentración de este metal en la estación de impacto, superándose el máximo permitido por la normativa y que corresponde en un $63 \%$ a cobre disuelto. Cabe destacar que en septiembre y diciembre el efluente superó el máximo de cobre total permitido por la normativa para descargas de residuos líquidos a cuerpos de agua fluviales. ${ }^{18}$ Sin embargo, solo en diciembre la parte disuelta del metal corresponde a más del $50 \%$ del total del metal. Las concentraciones de cobre total son más altas a las determinadas en el estudio de Gaete et al. ${ }^{20}$

En estudios realizados en el norte de Chile en el río Elqui (IV Región), y más al sur (VI Región) en el río Cachapoal, ${ }^{21,22}$ en los cuales se estudió el efecto de las explotaciones mineras sobre la calidad de sus aguas se determinaron concentraciones más altas de cobre total a las determinadas en el presente estudio, esta diferencia se explicaría debido a variaciones en los procesos productivos de las empresas mineras, en los tratamientos de los residuos líquidos generados, así como en diferencias de caudal de los ríos, ya que los ríos mas caudalosos y rápidos tienen una capacidad de dilución mayor.

Las concentraciones de molibdeno total determinadas superaron el máximo establecido por la normativa para agua destinada a riego. ${ }^{19}$ En abril, la fracción biodisponible, es decir, el molibdeno disuelto corresponde a más del $90 \%$ del metal total en todas las estaciones (Tabla 1). Estos niveles son similares a los determinados por Gaete et al. ${ }^{20}$ en el mismo sector. Las altas concentraciones de molibdeno determinadas en el efluente y en la estación de impacto evidencian el efecto del efluente minero sobre la calidad de las aguas estudiadas. La concentración máxima de hierro y zinc total establecida por la normativa para aguas destinada a riego no es superada en el presente estudio y es similar a la determinada por Gaete et al.,${ }^{20}$ y más bajas a las determinadas en un estudio realizado por la Direccion General de Aguas (DGA) en el mismo sector. ${ }^{23}$

En la Figura 2 se muestra la tasa de crecimiento a las $96 \mathrm{~h}$ de la microalga $P$. subcapitata, se observan efectos inhibitorios en la estación de impacto, posteriormente se recupera la tasa de crecimiento a niveles similares a los de la estación de preimpacto. Esta inhibición en la estación de impacto se debe a la descarga del efluente lo que generó en sus aguas receptoras altos niveles de conductividad y concentración de sólidos disueltos totales así como altas concentraciones de metales pesados, debido a que se encuentra aguas abajo a la descarga del efluente minero de la planta de molibdeno. En diciembre hubo $100 \%$ de inhibición de la tasa de crecimiento en las tres estaciones (Figura 2), lo que se puede atribuir a las altas concentraciones de metales pesados, especialmente cobre determinadas en este periodo (Tabla 1), lo que es esperable debido a que Bossuyt y Janssen ${ }^{24}$ y Cyrino et al. ${ }^{25}$ han determinado una concentración efectiva media, es decir concentración a la cual muere el $50 \%$ de los individuos de $\mathrm{IC}_{50}=6-439 \mu \mathrm{g} \mathrm{Cu} / \mathrm{L}$.

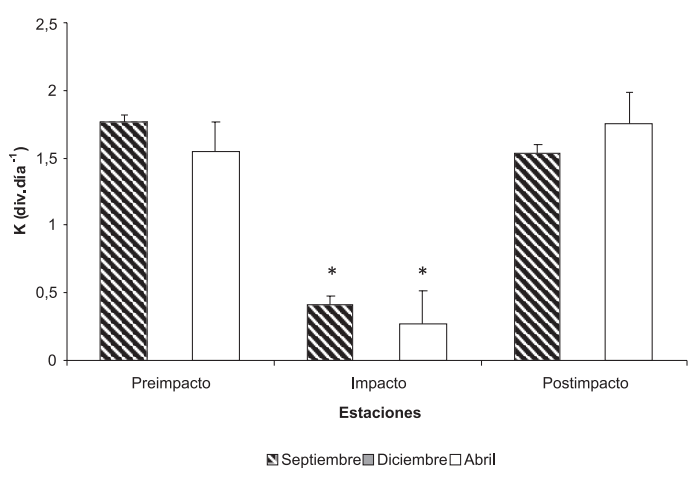

Figura 2. Tasa de crecimiento de P. subcapitata a las $96 \mathrm{~h}$. *: indica diferencia significativa con la estación de preimpacto en cada período de estudio. $(P<0.05)$

La exposición a altas concentraciones de metales pesados puede ocasionar la sobreproducción de especies reactivas de oxígeno induciendo la síntesis de enzimas antioxidantes como la catalasa. ${ }^{3} \mathrm{La}$ actividad de la catalasa aumenta en la estación de impacto, comparada con la estación de preimpacto (Figura 3). Los metales, especialmente 
Tabla 1. Parámetros fisicoquímicos determinados en los períodos de estudio

\begin{tabular}{|c|c|c|c|c|c|}
\hline \multirow[t]{2}{*}{ Parámetro } & \multirow[t]{2}{*}{ Período } & \multicolumn{4}{|c|}{ Estación } \\
\hline & & Preimpacto & Efluente & Impacto & Postimpacto \\
\hline \multirow[t]{3}{*}{$\mathrm{pH}$} & Septiembre & 8,20 & 7,07 & 7,84 & 8,18 \\
\hline & Diciembre & 6,40 & 7,20 & - & 6,51 \\
\hline & Abril & 7,15 & 6,80 & 7,92 & 7,00 \\
\hline \multirow{3}{*}{$\begin{array}{l}\text { Sólidos disueltos totales } \\
\text { [mg/L] }\end{array}$} & Septiembre & 140 & 1610 & 900 & 260 \\
\hline & Diciembre & 160 & 1490 & - & 230 \\
\hline & Abril & 150 & 1740 & 340 & 220 \\
\hline \multirow[t]{3}{*}{ Temperatura $\left[{ }^{\circ} \mathrm{C}\right]$} & Septiembre & 12,20 & 15,20 & 14,10 & 12,90 \\
\hline & Diciembre & 10,90 & 19,40 & - & 11,80 \\
\hline & Abril & 8,80 & 15,20 & 9,70 & 11,00 \\
\hline \multirow[t]{3}{*}{ Conductividad $[\mathrm{mS} / \mathrm{cm}]$} & Septiembre & 0,29 & 3,24 & 1,99 & 0,54 \\
\hline & Diciembre & 0,23 & 3,00 & - & 0,38 \\
\hline & Abril & 0,31 & 3,48 & 0,68 & 0,45 \\
\hline \multirow[t]{3}{*}{ Oxigeno disuelto $[\mathrm{mg} / \mathrm{L}]$} & Septiembre & 4,55 & 9,60 & 4,26 & 4,10 \\
\hline & Diciembre & 15,50 & 6,60 & - & 15,50 \\
\hline & Abril & 9,60 & 10,45 & 9,50 & 8,30 \\
\hline \multirow[t]{3}{*}{$\mathrm{Cu}$ total $\mu \mathrm{g} / \mathrm{L}$} & Septiembre & 36 & 2200 & 3800 & 107 \\
\hline & Diciembre & 15600 & 3965 & - & 15800 \\
\hline & Abril & 37 & 630 & 239 & 31 \\
\hline \multirow[t]{3}{*}{$\mathrm{Cu}$ disuelto $\mu \mathrm{g} / \mathrm{L}$} & Septiembre & 20 & 370 & 432 & 33 \\
\hline & Diciembre & 8650 & 2145 & - & 9090 \\
\hline & Abril & 34 & 426 & 152 & 29 \\
\hline \multirow[t]{3}{*}{ Mo total $\mu \mathrm{g} / \mathrm{L}$} & Septiembre & - & - & - & - \\
\hline & Diciembre & - & 443 & - & - \\
\hline & Abril & 11 & 892 & 125 & 45 \\
\hline \multirow[t]{3}{*}{ Mo disuelto $\mu \mathrm{g} / \mathrm{L}$} & Septiembre & - & - & - & - \\
\hline & Diciembre & 2,4 & 434,0 & - & 4,6 \\
\hline & Abril & 10,0 & 860,0 & 122,0 & 43,0 \\
\hline \multirow[t]{3}{*}{ Fe total $\mu \mathrm{g} / \mathrm{L}$} & Septiembre & 106 & 1459 & 2520 & 127 \\
\hline & Diciembre & 3885 & 2270 & - & 3550 \\
\hline & Abril & 47 & 1184 & 186 & 30 \\
\hline \multirow[t]{3}{*}{ Fe disuelto $\mu \mathrm{g} / \mathrm{L}$} & Septiembre & 29 & 162 & 252 & 23 \\
\hline & Diciembre & 61 & 123 & - & 66 \\
\hline & Abril & 17 & 806 & 16 & 17 \\
\hline \multirow[t]{3}{*}{$\mathrm{Zn}$ total $\mu \mathrm{g} / \mathrm{L}$} & Septiembre & $<\mathrm{LC}$ & 15,4 & 32,4 & $<\mathrm{LC}$ \\
\hline & Diciembre & 722,0 & 66,0 & - & 633,0 \\
\hline & Abril & 30,0 & 41,0 & 25,0 & 22,0 \\
\hline \multirow[t]{3}{*}{ Zn disuelto $\mu \mathrm{g} / \mathrm{L}$} & Septiembre & $<\mathrm{LC}$ & 9,8 & 8,5 & $<\mathrm{LC}$ \\
\hline & Diciembre & 650,0 & 54,0 & - & 745,0 \\
\hline & Abril & 19,0 & 27,0 & 13,0 & 10,0 \\
\hline
\end{tabular}

$<$ LC: Menor al límite de cuantificación. -: No se determinó el parámetro

el cobre, son conocidos como causantes de estrés oxidativo en plantas mediante la producción de especies reactivas de oxigeno. En las células eucariontes se han descrito varios mecanismos de tolerancia y detoxificación de metales pesados, entre los cuales se encuentra la activación de las defensas antioxidantes para proteger del estrés oxidativo inducido por los metales pesados, principalmente el cobre y el hierro. ${ }^{7}$ En la Tabla 2 se puede observar la correlación significativa entre las concentraciones totales y disueltas tanto de cobre como hierro con la actividad enzimática de la catalasa.

Se sabe que la catalasa juega un rol importante en la reducción 


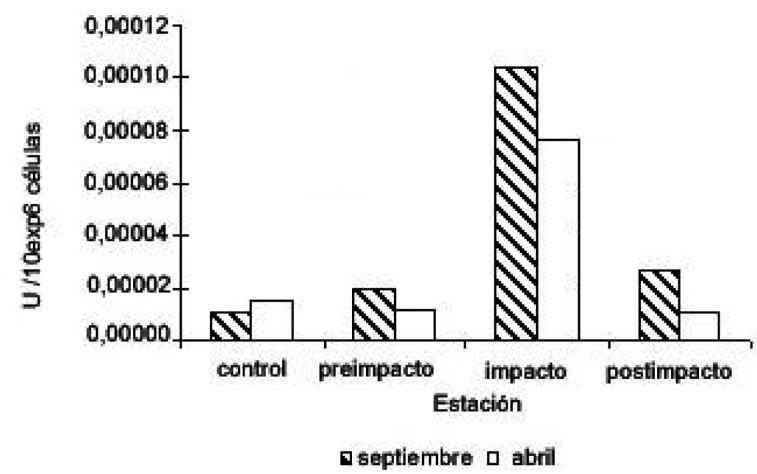

Figura 3. Actividad enzimática de la catalasa en P. subcapitata

del estrés oxidativo catalizando la oxidación del peróxido de hidrógeno $\left(\mathrm{H}_{2} \mathrm{O}_{2}\right)$. Por lo que el incremento en la actividad de esta enzima por cobre sugiere el aumento de la producción de $\mathrm{H}_{2} \mathrm{O}_{2} \mathrm{y}$ un marcado aumento de los niveles de catalasa y otras enzimas. Esto se encontró en la microalga Pavlova viridis, la actividad de la catalasa se incrementó al aumentar la concentración de cobre. ${ }^{4,6}$ El estudio realizado por Barata et al. ${ }^{26}$ sobre el impacto de las actividades industriales que descargan sus residuos al río Llobregat en España, encontraron una alta correlación entre las concentraciones de metales pesados y actividad enzimática antioxidante en estados larvales del mosquito tricoptera Hydropsyche exocellata, destacándose las enzimas catalasa y glutatión-S- transferasa. En el estudio de Contreras et al. ${ }^{17}$ la actividad de la catalasa en la macroalga Scytosiphon lomentaria expuesta a cobre fue siete veces mayor al control, mientras que Dewes et al. ${ }^{6}$ en su estudio donde investigó la sensibilidad de diferentes bimarcadores enzimáticos en la microalga Scenedesmus obliquus expuesta a cobre y fungicidas encontró que el estrés oxidativo inducido por cobre fue indicado por el aumento de la actividad de catalasa en la microalga determinando también que ésta enzima actúa como la más sensible y el más valioso de los biomarcadores enzimáticos.

Se ha comprobado que las respuestas de las enzimas antioxidantes al estrés producido por metales varía entre especies de plantas y el metal del que se trate. ${ }^{4}$ Los niveles de actividad de la catalasa determinados en el presente estudio son más bajos a los determinados en el estudio utilizando la microalga Pavlova viridis, donde se determinaron niveles entre 100 y $550 \mathrm{U} / 10^{6}$ células. ${ }^{4}$

Li et al.${ }^{4}$ encontró que el aumento de la lipoperoxidación, medida como producción de MDA, está asociada a altas concentraciones de cobre y zinc en la microalga $P$. viridis. En su estudio, Gorbi et al. ${ }^{27}$ determinó el aumento en alrededor de tres veces con respecto al control en el contenido de TBARS en la microalga Scenedesmus acutus expuesta a altas concentraciones de cromo. En el presente estudio se observó daño lipídico en la estación de impacto (Figura 4), que al igual que lo ocurrido con la catalasa, se correlacionó significativamente con las concentraciones de cobre y hierro.

La correlación significativa entre las concentraciones de algunos metales, como cobre y hierro, total y disuelto, en ambos períodos de estudio, sugiere que estos metales provendrían de la misma fuente de descarga (Tabla 2).

Existen muchos estudios sobre la respuesta de los sistemas antioxidantes de plantas ante estrés oxidativo por metales, pero los estudios en microalgas son muy pocos, ${ }^{4}$ por lo que los resultados obtenidos proveen de información para evaluar y comprender de mejor forma los impactos de la actividad minera local sobre la calidad de las aguas superficiales.

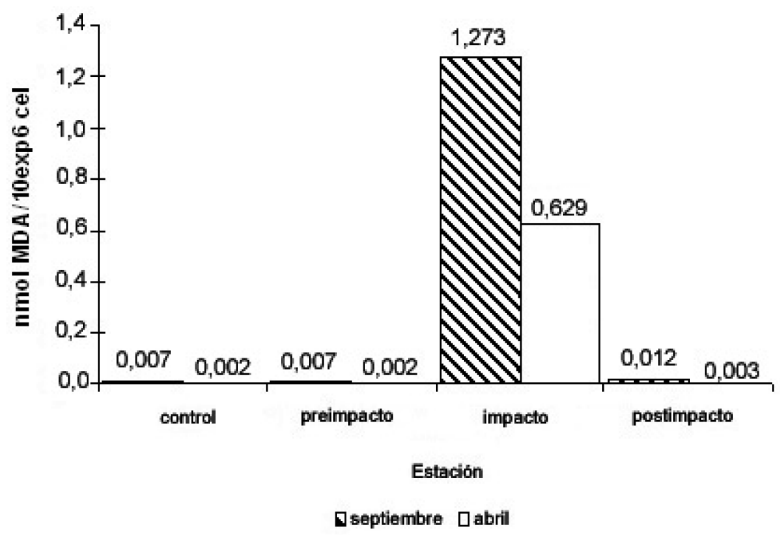

Figura 4. Daño lipoperoxidativo en P. subcapitata expuestas a aguas del río Blanco

Tabla 2. Correlación entre la concentración de metales pesados, tasa de crecimiento (k), actividad de la catalasa y productos de la lipoperoxidación (TBARS) en P. subcapitata

\begin{tabular}{|c|c|c|c|c|c|c|c|c|c|c|}
\hline & $\mathrm{k}$ & $\mathrm{pH}$ & $\mathrm{Cu}$ total & $\begin{array}{c}\mathrm{Cu} \\
\text { disuelto }\end{array}$ & Mo total & $\begin{array}{c}\text { Mo } \\
\text { disuelto }\end{array}$ & Fe total & $\begin{array}{c}\mathrm{Fe} \\
\text { disuelto }\end{array}$ & Zn total & $\begin{array}{c}\mathrm{Zn} \\
\text { disuelto }\end{array}$ \\
\hline $\mathrm{pH}$ & $-0,999 *$ & 1,000 & & & & & & & & \\
\hline $\mathrm{Cu}$ total & $-0,996$ & 0,992 & 1,000 & & & & & & & \\
\hline $\begin{array}{l}\mathrm{Cu} \text { diuelto } \\
\text { disuelto }\end{array}$ & $-0,997$ & 0,993 & $1,000 *$ & 1,000 & & & & & & \\
\hline Mo total & $-0,916$ & 0,902 & 0,949 & 0,946 & 1,000 & & & & & \\
\hline Mo disuelto & $-0,918$ & 0,903 & 0,950 & 0,947 & $1,000^{*}$ & 1,000 & & & & \\
\hline Fe total & $-1,000^{*}$ & $0,999 *$ & $0,997 *$ & $0,998^{*}$ & 0,923 & 0,925 & 1,000 & & & \\
\hline Fe disuelto & 0,993 & $-0,988$ & $-1,000^{*}$ & $-0,999 *$ & $-0,957$ & $-0,958$ & $-0,995$ & 1,000 & & \\
\hline Zn total & 0,025 & $-0,009$ & 0,118 & 0,107 & 0,424 & $-0,421$ & $-0,044$ & 0,143 & 1,000 & \\
\hline Zn disuelto & 0,072 & $-0,038$ & $-0,164$ & $-0,154$ & $-0,466$ & $-0,463$ & $-0,091$ & 0,189 & 0,999* & 1,000 \\
\hline Catalasa & $-0,995$ & 0,991 & $1,000^{*}$ & $1,000 *$ & 0,952 & 0,953 & 0,997 & $-1,000 *$ & $-0,126$ & $-0,172$ \\
\hline TBARS & $-0,992$ & 0,987 & $0,999 *$ & $0,999 *$ & 0,959 & 0,961 & 0,994 & $-1,000 *$ & $-0,152$ & $-0,198$ \\
\hline
\end{tabular}

*: Indica correlación significativa $(\mathrm{p}<0,05)$ 


\section{CONCLUSIÓN}

Los metales como el cobre y hierro asociados a la descarga del efluente de la industria minera generan efectos tóxicos en $P$. subcapitata, provocando daño lipídico, lo que a su vez produce la activación de defensas antioxidante como la actividad catalasa. La determinación de estos parámetros de daño oxidativo pueden ser adecuados biomarcadores de exposición en productores primarios en ecosistemas acuáticos afectados por descargas de metales.

\section{AGRADECIMIENTOS}

Esta investigación fue financiada por el Centro de Investigación y Gestión de Recursos Naturales CIGREN CID 01/2003, Dirección de Investigación, Universidad de Valparaíso.

\section{REFERENCIAS}

1. Vavilin, D.; Ducret, J.; Matorin, D.; Venediktov, P.; Rubin, A.; J. Photochem. Photobiol., B 1998, 42, 233.

2. Choo, K.; Snoeijsb, P.; Pedersén, M.; J. Exp. Mar. Biol. Ecol. 2004, 298,111 .

3. Valavanidis, A.; Vlahogianni, T.; Dassenakis, M.; Scoullos, M.; Ecotoxicol. Environ. Saf. 2006, 64, 178.

4. Li, M.; Hu, C.; Zhu, Q.; Chen, L.; Kong, A.; Liu, Z.; Chemosphere 2006, 62,565 .

5. Hidalgo, M.; Fernández, E.; Cabello, A.; Rivas, C.; Fontecilla, F.; Morales, L.; Aguirre, A.; Cabrera, E.; Rev. Biol. Mar. Oceanogr. 2006, 41, 155 .

6. Dewes, D.; Geoffroy, L.; Vernet, G.; Popovic, R. ; Aquat. Toxicol. 2005, 74,150 .

7. Ratkevicius, N.; Correa, J.; Moenne, A.; Plant, Cell and Environment 2003, 26, 1599.

8. Ait Alla, A.; Mouneyrac, C. ; Durou, C.; Moukrim, A.; Pellerin, J. ; Comp. Biochem. Physiol., Part C: Toxicol. Pharmacol. 2006, 143, 23.
9. Walsh, G.; Yoder, M.; Laughlin, L.; Lores, E.; Ecotoxicol. Environ. Saf. 1987, 4, 215.

10. Moreira-Santos, M.; Soares, A.; Ribeiro, R.; Ecotoxicol. Environ. Saf. 2004, 59, 164.

11. Chile, Instituto Nacional de Normalización; NCh 411/6. Of1998, 1998.

12. Chile, Instituto Nacional de Normalización;. NCh 2706.Of2002, 2002.

13. Dummermuth, A.; Karsten, U.; Fisch, K.; König, G.; Wiencke, C.; J. Exp. Mar. Biol. Ecol. 2003, 289, 103.

14. Rozowski, J.; Cuevas, A.; Castillo, O.; Marín, P.; Strobel, P.; Pérez, D.; San Martín, A.; Barriga, C.; Maiz, A.; Leighton, F.; Rev. Méd. Chile 2001, 129, 43.

15. Cargnelutti, D.; Tabaldi, L.; Spanevello, R.; Jucoski, G.; Battisti, V.; Redin, M.; Blanco, C.; Dressler, V.; de Moraes, E.; Teixeira, F.; Morsch, V.; Chitolina, M.; Chemosphere 2006, 65, 999.

16. Barros, M.; Granbom, M.; Colepicolo, P.; Pedersén, M.; Arch. Biochem. Biophys. 2003, 420, 161.

17. Contreras, L.; Moenne, A.; Correa, J.; J. Phycol. 2005, 41, 1184.

18. Chile, Ministerio Secretaría General de la Presidencia de la República; Decreto Supremo Nº 90, 2001.

19. Chile, Instituto Nacional de Normalización; NCh 1333.Of78, 1987.

20. Gaete, H.; Aránguiz, F.; Cienfuegos, M.; Quim. Nova. 2007, 30, 885.

21. Guevara, S.; Oyarzún, J.; Maturana, H.; Agric. Téc. 2006, 66, 57.

22. Richtera, P.; Segue, R.; Ahumada, I.; J. Chil. Chem. Soc. 2004, 49, 333.

23. Direccion General de Aguas. DGA; Diagnostico y clasificación de los cursos y cuerpos de agua según objetivos de calidad, Cuenca del río Aconcagua, 2004.

24. Bossuyt, B.; Janssen, C.; Aquat. Toxicol. 2004, 68, 61.

25. Cyrino, E.; Matos, R.; Roma, F.; Chemosphere 2004, 56, 369.

26. Barata, C.; Lekumberri, I.; Vila-Escalé, M.; Prat, N.; Porte, C.; Aquat. Toxicol. 2005, 74, 3.

27. Gorbi, G.; Torricelli, E.; Pawlik-Skowronska, B.; Sanita di Toppi, L.; Zanni, C.; Corradi, M.; Aquat. Toxicol. 2006, 79,132. 